\title{
Gestão da informação pública: um estudo sobre o Portal
}

Transparência Goiás

\author{
Rosana Campos ${ }^{1}$ \\ Denise Paiva ${ }^{2}$ \\ Suely Gomes ${ }^{3}$
}

Resumo: Esta pesquisa se propõe a compreender se e como o governo do Estado de Goiás trabalha para tornar a gestão pública mais transparente, através da divulgação eletrônica de suas ações, a partir da lei complementar 131/2009. O objeto desse estudo é o Portal Transparência Goiás e os canais e fluxos de informações que o alimentam. É um estudo exploratório com metodologia qualitativa. A pesquisa identificou falhas no processo de divulgação das informações e constatou que a transparência ainda tem sido tratada como uma questão menor pela gestão pública, ainda que tenham havido êxitos no processo. Palavras-chave: Estado, Accountability, Transparência, Gestão Pública, Informação.

\section{Introdução}

A reforma administrativa na década de 1990 redefiniu o papel do Estado brasileiro, que deixou de ser o responsável direto pelo desenvolvimento econômico e social via produção de bens e serviços, para se adequar a uma nova função de Estado gerencial. E, conforme Bresser Pereira (2001), ultrapassando esse caráter regulador, sendo também e, ao mesmo tempo, democrático e eficiente.

Nesse Estado gerencial e democrático, a questão da transparência passa a ter destaque como um fator de inibição da corrupção e consolidação democrática. Nesse sentido, "a transparência do Estado se efetiva por meio do acesso do cidadão à informação governamental, o que torna mais democrática a relação entre o Estado e a sociedade civil" (BRESSER-PEREIRA, 2004, p. 23).

Cada vez mais, a população tem cobrado uma postura ética e transparente dos negócios públicos. Nesse novo ambiente democrático, o controle social das ações governamentais, para além do voto, pode ser feito por meio de: controle parlamentar; controle de procedimentos no interior da burocracia e controle social. Nessa direção, o legislativo brasileiro tomou a primeira grande iniciativa de controlar o gasto público e expô-lo aos cidadãos. Em 2000, foi promulgada a Lei de Responsabilidade Fiscal (LRF), cujo principal objetivo foi formular regras
Recebido: 07.05.12 Aprovado: 28.11 .12

1. Universidade Federal de Santa Maria (UFSM).

E-mail: rosanascampos@yahoo.com.br

2. Universidade Federal de Goiás (UFG).

E-mail: denise@ cienciassociais.ufg. br

3. Universidade Federal de Goiás (UFG)

E-mail: suelyhenriquegomes@gmail. com 
de finanças públicas para a responsabilidade da gestão fiscal, com planejamento e transparência como seus pilares.

Entre outros pontos, a lei definiu que a gestão fiscal deveria ter ampla divulgação, inclusive em meios eletrônicos de acesso público. Desse modo, a legislação brasileira criou a figura do Portal Transparência. Porém, sem regulamentação, governo federal, estados e municípios não tiveram a obrigatoriedade de veicular as informações eletronicamente. Somente em 2009 foi promulgada a lei complementar 131, em vigor a partir de maio de 2010, que determinava a disponibilização em tempo real de informações pormenorizadas sobre a execução financeira e orçamentária da União, dos Estados, do Distrito Federal e dos Municípios.

Porém, mesmo antes da regulamentação, o governo federal e alguns governos estaduais e municipais adotaram iniciativas de controle da gestão pública. $O$ Portal Transparência Brasil, criado em 2004, serviu de referência aos demais portais, funcionando como um instrumento de prestação de contas da administração pública e, desse modo, incentivando o controle social. Seguindo os preceitos da LRF, a ideia desse portal foi a de que os cidadãos pudessem acompanhar a execução dos programas e ações do governo.

A grande discussão dessa temática não é apenas a criação dos portais e veiculação das informações orçamentárias e fiscais. O acesso a essa informação e a qualidade dela são discussões que foram levantadas pela LRF, mas somente colocadas em evidência com a entrada em vigor da lei complementar 131/2009, em maio de 2010, e da posterior avaliação dos portais estaduais e federal pela entidade da sociedade civil Contas Abertas. A organização criou um Índice de Transparência para verificar o operacionalização da lei complementar nos portais, a partir de três critérios: conteúdo, série histórica/frequência de atualização e usabilidade. Quesitos que caracterizam a transparência através de acesso e qualidade da informação.

O Índice de Transparência revelou que os portais ainda precisam melhorar em conteúdo e usabilidade, critérios que são obstáculos à participação do cidadão nesse instrumento/mecanismo de controle social. Essa constatação também foi feita por Culau e Fortis (2006) ao estudarem a inovações introduzidas pela LRF, entre elas o Portal Transparência Brasil. Conforme os autores, "a transparência das informações fiscais, orçamentárias, financeiras da administração pública mostram-se insuficientes para aproximar o cidadão do governante, a sociedade do Estado". Conforme os autores, a dificuldade parece estar associada a dois fatores: baixo nível de escolarização da população brasileira e ao hermetismo da linguagem técnica. 
Goiás foi um dos primeiros estados com a pretensão de implementar a transparência da gestão pública a partir da divulgação de informações, ainda em 2002, através de um portal. Porém sem formalização e sem procedimentos legais que pudessem fortalecer essa ferramenta de transparência, o portal foi suspenso e, somente com a exigência da lei complementar, voltou a ganhar espaço na administração pública goiana. No Índice de Transparência/2010, o portal do Estado de Goiás apresentou muitas fragilidades no cumprimento da lei, classificando-se em décimo segundo no ranking nacional.

Nessa direção, esta pesquisa propõe-se a compreender se e como o governo do Estado de Goiás trabalha para tornar a gestão pública mais transparente, através da divulgação eletrônica de suas ações. O objeto desse estudo é o Portal Transparência e os canais e fluxos de informações que o alimentam.

Para a realização desta pesquisa, partimos de um conjunto de informações que pudessem explicar os canais e fluxos da informação. Os obstáculos para a publicação das informações no portal foram importantes para compreendermos porque, ainda, o Portal Transparência Goiás não conseguiu adequar-se à lei e, mais do que isso, ser um instrumento de transparência de fácil acesso e de qualidade ao cidadão goiano.

\section{Etapas e metodologia da pesquisa}

Esta pesquisa é um estudo exploratório, realizado entre os meses de agosto de 2010 e janeiro de 2011. Foi dividida em duas etapas: reconhecimento do objeto de estudo e realização de entrevistas. Na primeira etapa, foram feitas visitas à equipe do Portal Transparência Goiás para conhecer o funcionamento do site. Além disso, foram realizadas pesquisas bibliográfica e documental na legislação pertinente ao objeto de estudo. Por fim, uma visita à equipe responsável pelo Portal Transparência Brasil, na Controladoria Geral da União, em Brasília.

Na segunda etapa, utilizou a metodologia qualitativa, a partir da técnica de entrevista em profundidade com os membros da equipe do portal e servidores públicos que, diretamente, estiveram ligados à elaboração do site.

Nessa etapa, propôs-se, então, a analisar: 1) a equipe, no que diz respeito à quantidade de membros e qualificação destes para a função, hierarquia e autonomia; 2) o caminho da informação: que informações, como são obtidas, quem decide, como se decide, garantia de qualidade, formato, linguagem; 3) a participação do cidadão: tipos de participação do usuário comum e do servidor público; 4) transparência: como os entrevistados entendem transparência. 
Este artigo está estruturado em duas partes: uma teórica, onde se discute os conceitos accountability e transparência; e a segunda, composta pela análise legal do portal, pela pesquisa qualitativa, com entrevistas em profundidade e, por fim, as considerações da pesquisa acerca do objeto estudado.

\section{As bases teóricas}

Se os homens fossem anjos, os governos não seriam necessários. Se os anjos governassem os homens, não seriam necessários controles externos nem internos sobre o

governo.

James Madison, Federalist Papers, 51

A célebre frase de Madison nos chama a atenção para a necessidade do constante controle dos homens no poder. Nos séculos XVII e XVIII, os clássicos da política já prenunciavam a importância das leis e instituições criadas pelos homens para reger as relações entre si, na compreensão de que, sem controle, os interesses individuais estariam acima do que desejavam os demais cidadãos de um modo geral.

A ideia de se ter mecanismos de controle do poder nasce com o desenvolvimento do Estado e se fortalece com a forma de governo democrática. É no Estado democrático que os cidadãos têm a possibilidade e a oportunidade de exigirem governos responsáveis e transparentes. Concepções que se fortaleceram a partir do momento em que o Estado foi compreendido enquanto uma organização político-administrativa com a função de prover serviços públicos e considerado como um aparato da sociedade. E não mais um todo, do qual a sociedade fazia parte.

Desse modo, essa sociedade, que exigiu igualdade política, liberdade individual, bem-estar, prosperidade, tem exigido, também, de seus governantes, responsabilidade sobre suas ações, através de controles internos e externos ao governo. $\mathrm{E}$, também, tem compreendido que a sua participação tem importância crucial em um bom governo. Estudos como o de Robert Putnan (2000) evidenciam a relação entre uma comunidade cívica participante e o desempenho de suas instituições. Estudando a Itália moderna, o autor verificou que, em regiões italianas onde havia sistemas dinâmicos de engajamento cívico, política horizontal e uma cultura dominada pela confiança, o desempenho das instituições era melhor. Ou seja, a chave do desempenho institucional é a participação cívica. $E$, desse modo, concluiu que uma democracia forte baseia-se na ideia de uma comunidade autônoma de cidadãos que são capazes de buscar objetivos comuns e de agir com reciprocidade, graças ao seu espírito cívico e às suas instituições participativas. 
É essa relação de responsabilidade de ambas partes, sociedade e governo, que permite ao Estado ser um instrumento, uma organização para possibilitar o bem-estar dos seus cidadãos. Essa responsabilidade mútua, chamada por europeus e norte-americanos de accountability, é o modo como sociedade e governo podem produzir um verdadeiro Estado de bem-estar social. A transparência, nesse contexto, é a ação do governo em dar satisfações de seus atos à sociedade. Explicar a ela como está governando, de que modo está administrando o bem público, mostrando como as receitas são adquiridas, como são gastas e porque são gastas. Justificando, desse modo, ao poder soberano (a sociedade), suas ações. Por isso, a importância de se compreender esses dois conceitos básicos e fundamentais para a boa relação Estado-sociedade.

\section{Accountability}

Na perspectiva da Ciência Política, o conceito de accountability ainda não apresenta consenso. Colocado ora como princípio, ora como mecanismo e, por vezes, como instrumento, accountability refere-se ao controle que os poderes estabelecidos exercem uns sobre os outros, mas, sobretudo, à necessidade que os representantes têm de prestar contas e submeter-se ao veredicto da população (MIGUEL, 2005).

Na tentativa de captar o que se pode entender e explicar como accountability, Guilhermo O'Donnell (1998) observou-a a partir de duas dimensões: horizontal - pressupõe uma relação entre iguais, de mútua vigilância entre os três poderes autônomos do Estado, por exemplo, agências reguladoras do executivo, o legislativo e o judiciário; vertical - pressupõe uma relação entre desiguais, seja sob a forma do mecanismo do voto ou sob outro tipo de fiscalização da sociedade com relação às ações do governo.

Mas O’Donnel é cético ao pensar em accountability na América Latina, um conceito que, para o autor, está muito ligado à poliarquia. $\mathrm{E}$ o fato de esta não ser um produto nativo do subcontinente explica, provavelmente, a ausência do conceito por aqui. Conforme O'Donnell, há uma simples reprodução. A defesa do autor de uma intrínseca relação entre accountability e democracia é influenciada pela análise de Robert Dahl (1971) de que a necessidade de que os agentes públicos, entendidos no sentido amplo da palavra, prestem contas de seus atos aos cidadãos só surge e faz sentido no contexto de uma democracia representativa contemporânea, ou melhor, em uma república pautada pelo princípio da igualdade intrínseca.

Desse modo, de acordo com O’Donnell, accountability é uma prática presente em democracias avançadas, que têm cidadãos mais participantes e mecanismos 
que compelem os detentores de cargos públicos a prestarem contas de seus atos, partindo do pressuposto de que não bastam os valores, são necessárias regras do jogo e restrições institucionais para o bom funcionamento das organizações.

Nesse sentido, o avanço da democracia promoveria a evolução de questões relativas ao controle de atividades públicas. E, conforme Ana Maria Campos (1990), somente a partir da organização de cidadãos vigilantes e conscientes de seus direitos, haveria condições para accountability. "Não haverá tal condição enquanto o povo se definir como tutelado e o Estado como tutor" (CAMPOS, 1990, p. 46).

E, pelo menos nesse ponto, a ciência política tem um consenso: é preciso ter um tipo de cidadão, o que participa efetivamente da coisa pública, para, então, serem formuladas demandas por accountability.

Accountability é, dessa maneira, um instrumento de controle da soberania popular sobre os atos do representante e dos agentes públicos em geral. Porém, como Andrade Mota (2006) chama a atenção, é, pois, necessário, entendê-la dentro de um contexto de governo representativo e não como um mecanismo de ação do governo do povo pelo povo. Pois, os representantes não vinculam suas convicções e ações aos interesses do povo meramente.

É claro que quebrar promessas tem uma carga negativa com possíveis sanções morais, porém a expectativa de que os cidadãos punam moralmente os agentes públicos não é suficiente para que estes produzam políticas consentâneas com os interesses daqueles. (MOTA, 2006, p. 14)

É por isso que, para Mota, considerando-se que, na realidade, os cidadãos não governam através de seus representantes, mas que os representantes, quando atuam, devem fazê-lo segundo interesse público, é necessário existir imposições legais-institucionais para assegurar tal conexão. Conforme a autora, a accountability é esse elemento-chave da conexão, possibilitando ao cidadão requisitar esclarecimentos sobre as decisões, que são discricionárias, com previsão de punição para o caso de não fazer, caso seja apurado algum dano. Nesse contexto de democracia representativa não são apenas os agentes públicos que devem ser controlados. De acordo com Mota, uma série de cargos burocráticos devem ser controlados, porque representam o interesse público.

Analisando o contexto brasileiro, Maria Vitoria Benevides (2005) também corrobora com a ideia da necessidade de uma mudança política com relação à participação do cidadão. Senão, o processo não funciona. Segundo ela, o governo está sendo cobrado, mas a participação do povo nesse processo é ainda reduzida. 
No Brasil, a palavra accountability tem sido traduzida por 'responsabilização'. E, conforme Bresser Pereira (2006), ela tem dois aspectos: afirma que os governos são responsáveis perante os cidadãos e, também, conforme o discurso predominante sobre o conceito, enfatiza o direito dos cidadãos de controlarem a ação dos governos. Sob o pressuposto de que os "se os homens fossem bons não necessitaria ter governo", Bresser Pereira evidencia a necessidade de controle interno e externo para que se tenha governos e administradores públicos responsáveis. E apresenta, sob o aval do Conselho Latino-americano de Administração para o Desenvolvimento (CLAD), como advém essa responsabilização. Conforme o autor, há duas formas clássicas: o controle de procedimentos, realizado pelos superiores hierárquicos e pelos sistemas de auditoria e o controle parlamentar. E mais duas formas modernas de responsabilização (accountability), o controle por resultado e o controle social. A tabela 1, elaborada em estudo do CLAD, evidencia os tipos de responsabilização e os agentes controladores.

Tabela 1 - Controladores e Responsabilização

Tipos de Responsabilização

\begin{tabular}{|c|c|c|c|c|}
\hline Controladores & Parlamentar & Procedimento & Resultado & Social \\
\hline Político & $\mathrm{X}$ & & $\mathrm{X}$ & \\
\hline Burocrata & & $\mathrm{X}$ & $\mathrm{X}$ & \\
\hline Sociedade & & & $\mathrm{X}$ & $\mathrm{X}$ \\
\hline
\end{tabular}

Fonte: CLAD, 2000

De acordo com o CLAD, esses controles clássicos e modernos constituem-se na divisão do poder para evitar sua concentração. O controle de procedimentos tem o objetivo de que normas e procedimentos legais sejam cumpridos. Um dos órgãos representativos desse controle é o Tribunal de Contas. O controle parlamentar é um tipo de controle mútuo entre os poderes executivo e legislativo e apresenta quatro mecanismos principais de controle: 1) submissão das nomeações realizadas pelo executivo a importantes cargos públicos à aprovação do legislativo; 2) controle na elaboração e gestão do orçamento e também da prestação de contas do executivo; 3) existência e o funcionamento pleno de comissões parlamentares destinadas a avaliar políticas públicas e a investigar a transparência dos atos governamentais; 4) audiências públicas - instrumento utilizado para se realizar uma discussão junto à sociedade sobre leis, programas e projetos que podem ser implementados. O controle social é feito através das eleições, conselhos em que a sociedade civil participa e audiências públicas. Já o controle por resultados introduz a questão das metas a serem atingidas por cada provedor do bem público. Para o CLAD, esses quatro tipos de controle são fundamentais para uma boa governança, no sentido de que o bem público, sendo fiscalizado por vários atores políticos e sociais, é melhor administrado e mais 
voltado às demandas da sociedade.

Numa visão unilateral, de resposta do governo à sociedade, sem mencionar a importância da participação societal neste processo, Peruzzotti e Smulovitz (2000) analisam accountability como a capacidade de garantir que os funcionários públicos sejam answerable (responsáveis) por seu comportamento, no sentido de serem obrigados a informar e justificar sobre suas decisões e, eventualmente, de serem punidos por essas decisões.

Schedler apud Horochovski (2008) também compartilha dessa noção de accountability como uma responsabilidade do governo em prestar contas à sociedade. Para ele, accountability tem duas dimensões: answerability - compreendida como a capacidade de resposta dos governos, a obrigação que os agentes públicos têm de informar e explicar seu atos; e enforcement - a capacidade das agências de accountability de impor sanções aos agentes que violem os deveres públicos, ou seja, diz respeito essencialmente à punição.

Nos universos governamental, econômico, administrativo e contábil, accountability é usualmente compreendida como a obrigação de membros de um órgão administrativo ou representativo de prestar contas a instâncias controladoras ou a seus representados. Imprimiu-se a noção de que quem desempenha funções de importância na sociedade deve, regularmente, explicar o que está fazendo, por que faz, quanto gasta e o que vai fazer a seguir. Porém, ainda pouco se argumenta sobre a importância da população para que os mecanismos de controle realmente funcionem. Desse modo, ainda é necessário questionar os motivos pelos quais a população ainda não está totalmente integrada nesse processo de accountability, que é fundamental para o funcionamento do regime democrático. Faz-se também necessário questionar, também, se a população tem acesso aos atos dos agentes públicos, já que a informação é um pressuposto básico da transparência dos negócios públicos em uma verdadeira e legítima democracia. Nesse sentido, a transparência é a mola propulsora da accountability e a garantia de controle social dos atos públicos.

\section{Transparência}

Transparência é o fluxo crescente de informações econômicas, políticas e sociais, apresentando os seguintes atributos: 1) acessibilidade aos meios de informações, aliada à proficiência; 2) relevância da informação apresentada; 3) qualidade e confiabilidade, abrangência, consistência e relativa simplicidade em sua apresentação (VISHWANATH \& KAUFMAN, 1999).

A transparência é composta pelo princípio da publicidade e pelos subprincípios 
da motivação e participação popular na gestão administrativa, uma vez que todos apontam para a visibilidade da atuação administrativa, que inspira a produção de regras, procedimentos e leis, como a Lei de Responsabilidade Fiscal.

Os juristas entendem que o princípio da transparência concretiza o princípio da cidadania e oferece meios para que os cidadãos brasileiros possam não somente compreender a gestão dos recursos públicos, como efetivamente participar desse processo administrativo. Desse modo, não se concebe transparência apenas como uma obrigação formal. Mas uma necessidade para dar legitimidade às decisões do administrador, fundamentando suas opções técnicas e políticas em matéria de planejamento fiscal. Entende-se também que a participação da população e das entidades interessadas seja importante para o processo. Mas essa participação exige conhecimento prévio, explicação minuciosa, esclarecimento de quem exibe a conta. Afinal, transparência é mais do que a publicidade do ato, que se resume à publicação de atos do poder público no veículo oficial de imprensa. O princípio da transparência diz respeito à abertura e compartilhamento de informações, que torna o público mais capaz de decidir e fazer as escolhas políticas, aumenta a accountability e reduz o âmbito da corrupção.

Nesse sentido, a transparência não deve ser incumbência de alguns gestores do órgão público, mas sim uma política organizacional, tendo em vista o relacionamento dentro da estrutura hierárquica do órgão público. O sucesso dessa política organizacional passa pela gestão da informação e pelo desenvolvimento da tecnologia da informação, ambas oferecem novas possibilidades de ganhos de transparências nas organizações públicas.

A Organização para Cooperação e o Desenvolvimento Econômico (OCDE, 2001) argumenta que a transparência, entendida como a abertura sobre concepção, formulação e implementação de políticas, é um elemento chave da boa governança. Observa também que, nos regimes democráticos, a transparência é um dos elementos essenciais para o desempenho exitoso do governo. E a habilidade de ver como o governo usa o dinheiro público é fundamental para a democracia.

\section{Entendendo a Lei de Responsabilidade Fiscal}

A Lei de Responsabilidade Fiscal, de 2000, foi um marco no processo de transparência e responsabilidade dos atos públicos no Brasil. Representou uma tentativa de criação de compromisso com a gestão fiscal responsável e com o equilíbrio das contas públicas. Além de ser um mecanismo de controle de recursos públicos. Nesse processo, a transparência é vista como um dos pilares da LRF, já que é compreendida como produção e divulgação sistemáticas de informações, com o objetivo de aproximar Estado e sociedade, ampliando o acesso do cidadão 
às informações sobre a gestão pública.

A LRF teve como finalidade formular regras de finanças públicas para a responsabilidade da gestão pública, através da instituição do planejamento e da transparência. Ela recai sobre os três poderes, o Ministério Público, as três esferas de governo e todos os órgãos e entidades pertencentes à administração pública.

Entre outras definições, como um instrumento de accountability, a LRF prevê que a transparência assegura-se mediante incentivo à participação popular e à realização de audiências públicas e durante os processos de elaboração e discussão dos planos, lei de diretrizes orçamentárias e orçamentos. Uma outra regra de transparência, importante na Lei, é a disponibilidade das contas da máquina estatal e governamental para os cidadãos.

Nesse sentido, a Lei determina os seguintes instrumentos de transparência: 1) transparência fiscal - planos, lei de diretrizes orçamentárias e orçamentos - prestação de contas e respectivos pareceres prévios; 2) relatório resumido de execução orçamentária e relatório de gestão fiscal; 3) versões simplificadas desses documentos.

A Lei determina, ainda, em diversos dispositivos, que as informações apuradas sejam divulgadas em meio eletrônico, promovendo a ampliação do acesso dos cidadãos, mediante o acesso à Internet. Foi a partir desses dispositivos que o governo federal criou o Portal da Transparência, que veicula informações sobre execução orçamentária e financeira dos ministérios. O portal atua, ainda, como instrumento de publicização da prestação de contas dos ministérios, revelando à sociedade como os recursos têm sido aplicados.

Culau e Fortis (2006) avaliam que o saldo da lei tem sido positivo e observam que se está criando no Brasil uma cultura de divulgação sistemática, organizada e inteligível de dados de interesse coletivo. Porém, argumentam, há ainda dificuldade dos cidadãos de acesso à máquina pública. Conforme os autores, apesar da tendência rumo à flexibilização, agilidade e transparência, os entraves são poderosos.

De acordo com Culau e Fortis, a transparência das informações fiscais, orçamentárias e financeiras da administração pública mostra-se insuficiente para aproximar o cidadão do governante, a sociedade do Estado. Para os autores, essa dificuldade parece estar associada a dois fatores: baixo nível de escolarização da população brasileira e o hermetismo da linguagem técnica. Desse modo, os autores defendem a importância da informação acessível porque o baixo nível de politização do brasileiro e a natureza eminentemente técnica das informações divulgadas impedem o entendimento popular. 
Ainda que lentamente, algumas iniciativas têm sido tomadas. Em 2009, foi aprovada a lei complementar 131, que regulamentou a disponibilização das contas públicas e outras informações fiscais e orçamentárias na Internet, em tempo real, para todos os municípios com mais de cem mil habitantes. A lei entrou em vigor em maio de 2010. Com a facilidade de acesso à Internet, essas informações públicas têm sido cada vez mais disponibilizadas como um meio de o cidadão ter acesso rápido e gratuito sobre as ações do governo. Mas a pergunta é: será que funciona? Um portal é uma ferramenta de controle social? Os cidadãos estão utilizando como uma forma de monitoramento para saberem como e onde está sendo gasto o dinheiro público?

Em seu relatório sobre a Transparência nos Estados Unidos/Califórnia, a Calpirg Education Fund (2009) apontou avanços na transparência das contas públicas a partir do uso da Internet como ferramenta online para o bom governo. Porém, a empresa chama a atenção para o uso correto, a fim de gerar bons resultados. 0 relatório verificou três características que foram responsáveis por esse avanço: 1) um portal amigável/compreensivo/agradável; 2) um site para os habitantes saberem as informações que desejam; e 3) os dados fáceis de serem encontrados no site. Cerca de 29 estados americanos adotaram esses critérios e apresentam seus orçamentos online, em um único site, fornecendo aos seus habitantes uma base de dados sobre os gastos do governo, com direito a acesso compreensivo, centralizado e de busca fácil.

Para os autores do relatório, esse movimento, intitulado Transparency 2.0, dá aos cidadãos o acesso a um conjunto de informações cruciais do governo. 0 uso da Internet como uma ferramenta de transparência, conforme os autores, traz muitos benefícios: promove o aumento do engajamento cívico, tem um baixo custo de criação, poupa dinheiro dos cofres públicos, com menos tempo e menos dinheiro para disponibilizar as informações, melhor alvo para despesas, porque se pode ver os projetos que falharam e cobrar para o governo investir em outros e há uma melhor coordenação dos contratos do governo.

No Brasil, os estudos dos benefícios da Internet para a transparência são recentes, bem como esse fenômeno. $\mathrm{E}$ as pesquisas estão mais voltadas para a compreensão dos governos eletrônicos, portais dos órgãos, como os estudos de Jorge Santana Jr. et al (2009); José Pinho (2008); Luiz Akutsu e José Pinho (2002) e tantos outros. Mas os trabalhos evidenciam que ainda há pouca democracia nesse processo.

Com o pressuposto de que governos politicamente mais avançados tenham mais interesses e preocupações em criar um portal mais informativo, transparente e participativo, José Antonio de Pinho (2008) analisou dez portais de governos estaduais com os maiores PIBs do país, entre eles o do Estado de Goiás, a partir 
de quatro critérios: condições de acesso ao portal, grau de informação propiciado pelo portal, transparência do portal e participação popular. E verificou que os portais, de um modo geral, têm recursos tecnológicos adequados, boas condições de navegabilidade, mas, segundo o autor, "não se localizou transparência

e diálogo aberto com o público, ou seja, (...) estamos longe de um provimento democrático de informações".

Conforme Pinho, a partir da análise dos portais, não se visualiza possibilidade de capacitação política da sociedade. "Os governos nos casos analisados pouco se abrem para a accountability, a não ser aquela já fixada pela lei (...) não apresentam avanços substanciais do ponto de vista da abertura à participação popular" (PINHO, 2008, p. 491-2). Portanto, para o autor, no Brasil, o desenvolvimento econômico não pressupõe maior transparência. De acordo com Pinho, essa é uma questão de desenvolvimento político. "Temos muita tecnologia (...) mas pouca democracia".

Analisando portais dos poderes e órgãos dos Estados brasileiros e do Distrito Federal, Jorge Santana Jr. et al (2009) observaram relações entre níveis de transparência e indicadores socioeconômicos. Os autores avaliaram os portais com base nos instrumentos de transparência estabelecidos pela Lei de Responsabilidade Fiscal e concluíram o seguinte: 1) a análise descritiva dos dados demonstrou existir uma baixa aderência à integralidade das exigências legais de transparência fiscal eletrônica nos sites dos poderes estaduais examinados, mas 2) a análise estatística evidenciou uma associação entre indicadores socioeconômicos e níveis de transparência, conforme a lei, em $82,86 \%$ dos casos pesquisados, desconsiderando os ministérios públicos estaduais.

Na referida pesquisa, os portais dos poderes e órgãos do Estado de Goiás chamam a atenção por apresentarem baixos níveis de transparência fiscal, dentro dos limites da lei. No ranking dos 26 Estados e do Distrito Federal, Goiás ocupou a vigésima segunda colocação, perdendo apenas para estados como Roraima e Amapá, já que outros estados empataram entre si, à frente de Goiás, recebendo a mesma colocação.

As duas pesquisas, apesar de chegarem a resultados diferentes quanto à relação desenvolvimento econômico e transparência, trazem um elemento em comum em suas conclusões: a transparência, seja ela analisada do ponto de vista legal ou a partir de critérios estabelecidos pelos pesquisadores, não tem sido uma prática dos governos estaduais no Brasil.

\section{A legalidade no Portal Transparência Goiás}

Estudos sobre governo eletrônico no Brasil já evidenciam a preocupação de 
mostrar o cumprimento da lei nos portais (SANTANA Jr, 2009; PINTO, 2008; CUNHA, 2005) e uma estrutura adequada para acesso fácil e com informação de qualidade ao cidadão. A pesquisa da organização Contas Abertas revelou, através do Índice de Transparência, que ainda há muita ausência de transparência nas contas públicas, resultado de uma baixa aderência à legislação e de estabelecimento de critérios estruturais para o acesso fácil, rápido e confiável de informações sobre execução orçamentária e financeira.

No âmbito legal, o Portal Transparência Goiás, no modelo atual constituído a partir de 2009, é definido pela lei complementar federal 131/2009, o decreto estadual n. 6.965/2009 e a portaria da Secretaria da Fazenda do Estado de Goiás n. 1.332/2009. Com relação à lei complementar 131/2009, o portal não atende a algumas determinações dos três artigos da lei. Por exemplo, o incentivo à participação exigido pela lei é ainda um elemento superficial no portal. Há apenas o link Fale Conosco, telefones e e-mail de contato. Informações pormenorizadas sobre a execução orçamentária e financeira também não estão contempladas no portal e as despesas não foram atualizadas, no exercício de 2011.

Com referência ao decreto n. 6.965, há exigência de que os seguintes dados sejam disponibilizados: I - dados da arrecadação estadual; II - gastos efetuados pela administração pública estadual; III - repasses de recursos estaduais aos Municípios; IV - operações de descentralização de recursos orçamentários em favor de pessoas naturais ou de organizações não governamentais de qualquer natureza; $V$ - operações de crédito realizadas por instituições financeiras oficiais de fomento; VI - outros procedimentos de interesse do controle social. Dessa relação enumerada, apenas os itens IV e V não foram verificados no portal.

O decreto ainda determina, em seu parágrafo segundo, que órgãos e entidades do poder executivo devam disponibilizar à Superintendência de Controle Interno, responsável pela gestão do site, o acesso aos dados necessários à plena consecução dos objetivos de transparência e do controle social das ações governamentais. Mas, conforme informações coletadas nas entrevistas em profundidade com a equipe do portal, essa rede de interação é ainda incipiente. Também não há cronograma de execução das ações de divulgação, como exige a lei.

Por fim, observou-se que alguns artigos da portaria 1.332/2009, da Secretaria da Fazenda do Estado de Goiás, que disciplinam a divulgação de dados e informações dos órgãos e entidades da administração pública estadual na Internet não estão sendo cumpridos. O "banco de dados da transparência" não tem sido alimentado, como determina o artigo 5 da portaria, que estipula um prazo máximo de 15 dias após o encerramento de cada mês para órgãos e entidades do poder executivo mandarem informações orçamentárias e fiscais ao banco. Talvez, em razão do não cumprimento do artigo 5 da referida portaria, a Superintendência 
de Controle Interno não tenha divulgado os dados no prazo adequado, como determina o artigo 6 .

O artigo sétimo da portaria 1.332/2009 determina que órgãos e entidades das administrações direta e indireta devam inserir em suas páginas eletrônicas o acesso ao Portal Transparência Goiás. Dos 54 sítios mantidos pelo governo do Estado de Goiás, cerca de 28 não disponibilizam o acesso ao Portal Transparência Goiás. Entre eles estão: Secretaria da Educação, Secretaria da Saúde, Ministério Público Estadual, Tribunal de Contas do Estado, Tribunal de Justiça, Tribunal Regional Eleitoral, entre outros.

A portaria também exige a atualização mensal de informações sobre a arrecadação estadual, a execução orçamentária e financeira, licitações, contratos, convênios, despesas com passagens e diárias e procedimentos administrativos disciplinares dos órgãos e entidades da Administração Pública Estadual, porém estas não são divulgadas e atualizadas mensalmente.

As informações relativas à execução orçamentária e Financeira, exigidas no artigo 12, para que sejam disponibilizadas no Portal Transparência Goiás, não apresentam valores atualizados para percentual de recursos pagos comparados aos autorizados e um percentual de recursos pagos comparados aos empenhados. Diárias e passagens pagas a servidores públicos em deslocamento, em razão do trabalho, ou a colaboradores eventuais em viagens no interesse da administração, não constam no portal como foi definido pelo artigo 17 da portaria.

Com respeito aos Procedimentos Administrativos Disciplinares, observa-se que os seguintes itens não são devidamente cumpridos, como exigido no artigo 18 da portaria, no que se refere a informações disponibilizadas no portal: quantitativo, percentual e gráfico de sindicâncias finalizadas com oferecimento de denúncia; quantitativo, percentual e gráfico de sindicâncias finalizadas com sugestão de arquivamento dos autos; quantitativo, percentual e gráfico de processos finalizados; quantitativo, percentual e gráfico de servidores absolvidos.

A partir da análise do cumprimento da legislação, verifica-se que a transparência ainda é uma prática em desenvolvimento no Estado de Goiás. Muitas informações para que as ações governamentais tornem-se públicas já foram disponibilizadas. Mas há, ainda, a necessidade de uma melhor adequação à legislação, observando que a transparência é um direito constitucional.

O Portal Transparência: uma descrição das decisões, canais e fluxos da informação

Nesta etapa da pesquisa, o objetivo foi compreender os canais e fluxos das 
informações disponibilizadas no portal, para explicar o desconhecimento do portal, a ausência de informações relevantes para o controle social e o difícil acesso a essa ferramenta de transparência da gestão governamental no Estado de Goiás. Esta etapa da pesquisa foi dividida em cinco temáticas: equipe, o caminho da informação, o portal, a participação do cidadão e, por fim, a compreensão sobre transparência. Foram realizadas entrevistas em profundidade com membros da equipe e pessoas que, de forma direta, ajudaram na construção e manutenção do portal. Para que os entrevistados sejam preservados, utilizou-se códigos para determiná-los (B, E, V e O).

\section{a) Equipe}

O Portal transparência é um produto da Gerência de Ética e Transparência, que, por sua vez, pertence à Superintendência de Controle Interno, vinculada à Secretaria da Fazenda do Estado de Goiás. Para manter e atualizar o Portal, a Gerência conta com quatro servidores públicos, com as seguintes responsabilidades: um gerente, formado em Direito; um coordenador de pesquisa e divulgação, com formação em Educação Física e mestrado em Sociologia; uma secretária, com segundo grau; e um assessor, formado em agronomia, com mestrado em Planejamento e desenvolvimento, pela FGV. Esse funcionário presta assessoria na divulgação e promoção da ética junto aos funcionários públicos.

Essa composição é considerada insuficiente tanto em termos quantitativos, quanto qualitativos. A equipe desejada, na perspectiva dos entrevistados, deveria contar com uma pessoa formada em comunicação social e duas ou três pessoas da área de informática com dedicação integral ao Portal. O entrevistado B complementa que esses profissionais deveriam ser "reeducados na questão de ética e transparência para poderem fazer uma discussão maior em termos instrumentais".

Para o entrevistado E, além dos profissionais acima citados, o portal deveria contar com uma assessoria jurídica e assessoria orçamentário-contábil, com a finalidade de se ter uma equipe multidisciplinar. Apesar de ter status de gerência, o que hierarquicamente poderia limitar a ação da equipe responsável pela transparência, os seus integrantes consideram que essa situação, até o presente momento, não afetou a sua autonomia no desenvolvimento das atividades. Entretanto, tal autonomia é relativizada pelos entrevistados $B$ e $E$, conforme fala a seguir:

(...) é a mesma coisa de você buscar informação na sua diretoria. Você está num nível hierárquico mais baixo. Então, isso tem uma determinada dificuldade, sem dúvida. Tanto 
que hoje a maioria dos estados tem sua controladoria. Eu acho que Goiás deve partir para ter a sua. Independente. Quando tá de forma hierárquica, sob a tutela do secretário da fazenda, o negócio, mesmo com todo esforço, você perde a autonomia. (Entrevistado B)

Como estamos numa posição hierárquica inferior, ou seja, não existe mais o Gabinete de Controle Interno ou uma Controladoria que está ligada diretamente ao governador, nós estamos em segundo escalão do governo. Quando solicito uma informação para o primeiro escalão, o secretário do estado, ela não se sente na obrigação nem de responder. Então, é como se eles não tomassem conhecimento. (Entrevistado E)

O fato de o Controle Interno ter deixado de ser um Gabinete, com poder de Secretaria de Estado, para ser uma superintendência, dificulta a obtenção, junto às outras secretarias, das informações que serão disponibilizadas no portal. A comunicação com os demais órgãos e unidades governamentais e a agilidade no acesso e disponibilização das informações ficam prejudicadas. Além disso, segundo fala do entrevistado $\mathrm{V}$, "existe um risco de um secretário cercear aquilo que a gente quer demonstrar".

\section{b) Caminho da Informação}

\section{Que informação disponibilizar}

O Portal Transparência, em cumprimento às leis e portarias, fornece basicamente informações fiscais. São informações sobre receitas e despesas, transferências para os municípios, salários, cargos e lotação dos servidores, mas em tabelas diferentes. Além disso, são disponibilizadas informações sobre diárias, convênios e despesas específicas, que a equipe do portal caracterizou como interessantes para serem divulgadas ao cidadão, referindo-se a gastos com combustível, lubrificantes, publicidade, medicamentos, grandes fornecedores do estado, etc.

As informações disponibilizadas no Portal Transparência são obtidas, em sua maioria, através do SIOFNET, o Sistema de Execução Orçamentária e Financeira do Estado do Estado de Goiás. Além dessa fonte, que fornece, segundo o entrevistado $E, 80 \%$ das informações do portal, os dados são coletados também no SARI, Sistema de Arrecadação das Receitas Estaduais e o SRH, Sistema de Recursos Humanos. A equipe do site utiliza uma ferramenta própria para a extração dos dados, o Business Object (BO). 
Apesar da lei complementar 131/2009, do decreto estadual 6.965/2009 e da portaria da Secretaria da Fazenda/GO 1.332/2009, dentro da equipe, não há critérios sistematizados para a definição de informações que são disponibilizadas no portal.

\section{Quem decide e como se decide}

As falas dos entrevistados evidenciam que não há pesquisas e não há parâmetros para a escolha de informações que não são exigidas pela legislação. A decisão, nesse caso, é o resultado de algumas observações, ideias viáveis de serem executadas e a "imaginação" do que o cidadão gostaria de ler no portal sobre as ações do governo. Os depoimentos abaixo ratificam essas observações.

A informação é definida verificando a experiência de outros Estados. A gente vê o que os outros Estados estão colocando no portal. Tem também um portal que se chama Índice de Transparência, que ele dita uns requisitos que ele acha que é adequado e ideias que surgem em reunião com a equipe. (Entrevistado E)

O depoimento do entrevistado $\mathrm{V}$ também confirma essa evidência

Aí, a gente fez umas tabelas, algumas despesas que o cidadão interessa mais em tomar conhecimento, como que o Estado gasta (...). Eu ficava aqui imaginando o que eu gostaria de saber sobre os gastos do Estado (...).

Dentro da equipe é sempre o gerente quem decide qual e como a informação será disponibilizada. Porém, o entrevistado $\mathrm{E}$ afirma que os demais integrantes têm autonomia para sugerir, já que todas as decisões são tomadas em reunião. Mas o depoimento do entrevistado $\mathrm{V}$ deixa claro que, além dessa instância de tomada de decisão, há outras superiores, a quem o gerente se reporta.

Eu sempre que bolo alguma coisa, eu levo para os superiores, né, porque a gerência está dentro da superintendência dele. (Entrevistado V)

\section{Interação}

Os entrevistados evidenciaram que a interação com as demais unidades governamentais é tranquila, principalmente pela existência de uma portaria que regulamenta o assunto. Em algumas secretarias, existe uma pessoa que é ponto 
de referência para o fornecimento das informações especificadas na portaria. Conforme os entrevistados, os requisitos mínimos exigidos pela legislação estão no portal e as melhorias que estão sendo implementadas são de iniciativa da própria equipe. $E$, nesse sentido, eles enfrentam dificuldades para coletar informações. Um dos integrantes relatou a burocracia que necessita percorrer para ter acesso a uma informação, conforme fala a seguir, pode levar quatro meses para uma conversa inicial para o repasse de informação:

(...) muito a dificuldade de que eu falo é acessibilidade. Eu preciso solicitar uma audiência com o gerente de convênios da Seplan, por exemplo. E aí, eu tenho que solicitar para o meu superintendente solicitar para o secretário da fazenda, que vai solicitar pro secretário da Seplan, que vai orientar o gerente dele a me receber, quando possível for. (Entrevistado E)

Para o entrevistado A, a resistência no fornecimento das informações solicitadas é mais uma questão da incipiência do processo, da falta de costume de compartilhamento e do custo dessas informações, que necessariamente uma atitude deliberada das unidades e órgãos do Estado. Essa resistência é minada na medida em que a equipe faz "diligências" junto aos diferentes segmentos. Segundo o entrevistado A, a resistência é uma questão cultural. Para ele, a interação não é fácil:

No início existe toda aquela coisa de proteção da informação ainda. Às vezes da dificuldade, de custo de transação, vamos dizer assim, é muito elevado. Você sair daqui e chegar em uma unidade e dizer: olha eu quero todas as suas informações no formato tal, assim, simplificada, desta forma. As pessoas assustam. Eles já têm os trabalhos deles e acredito que isso aí vai ser uma implantação de uma cultura, não vai ser da noite para o dia que eles vão conseguir isso não. Mas já tem uma ação direcionada para isso. Para essa integração. Todos os órgãos têm que integrar as informações deles aqui com o controle interno. (Entrevistado A)

As solicitações de fornecimento de informações extralegislação esbarram na rotina de trabalho de cada servidor, que não vê como prioridade o repasse desse tipo de dados, uma vez que não está previsto na lei, conforme o entrevistado $\mathrm{E}$. É nessa perspectiva que os entrevistados acreditam ser necessária uma sensibilização junto aos servidores públicos em relação à sua colaboração na disponibilização de informações, além daquelas meramente previstas em lei. 


\section{Informações que deveriam ser acrescentadas no portal}

Há unanimidade com relação a ausência de algumas informações importantes que poderiam ser de interesse do cidadão, como por exemplo:

As obras que o governo inicia ou que licita com objetivo político e não dá continuidade (...) teria o ano que ela iniciou, o mês e o ano que ela iniciou; quanto foi gasto, quando foi paralisada. Nós temos uma gerência aqui de engenharia de obras e serviço de engenharia que a gente ia pedir a ajuda deles para a gente quantificar mais ou menos o prejuízo que aquilo causou. (Entrevistado $\mathrm{V}$ )

Eu acho que falta uma explicação da informação. Por exemplo, a [empresa $x$ ] recebeu $\mathrm{R} \$ 500.00,00$. Tudo bem. Pagou uma, pagou duas, quer dizer, é uma planilha orçamentária. Então recebeu $\mathrm{R} \$ 500.00,00$. Qual foi a ponte que ela fez? Onde está esta ponte? Entendeu? Eu acho que de uma forma mais clara para as pessoas realmente praticarem o controle social. (Entrevistado B)

Para o entrevistado $E$, deveria haver maior detalhamento no repasse de recursos, "explicando não apenas o resultado final, não só como saiu o serviço, mas como ele é feito". O entrevistado E sugere que seja incluído o que ele denomina de "mapa de atividades do Estado", que seria um guia para orientar o cidadão na busca de informações de serviços comuns e também mais específicos.

\section{O formato e linguagem da informação}

Um dos objetivos do gerente de Ética e Transparência ao assumir o cargo era colocar as informações isentas e de forma amigável, para permitir ao cidadão se posicionar frente a temas polêmicos. No entanto, há um consenso entre os entrevistados de que a linguagem da informação ainda é excessivamente técnica e, portanto, pouco "palatável" para o cidadão comum.

O entendimento das informações disponibilizadas dependeria do grau de familiaridade do usuário do portal com os termos técnicos e sua experiência com a estrutura do portal ou sua navegabilidade.

(...) é uma linguagem difícil ainda. E a navegabilidade também é difícil. Tem site muito mais fácil de navegar. (...) Temos que melhorar o site. O objetivo é este - botar numa linguagem de acesso universal. (Entrevistado $\mathrm{B}$ ) 
Para o entrevistado E, isso implicaria que: "essa informação tem que ser reescrita de forma mais acessível ao público em geral que tem só o nível médio ou básico"

As informações são disponibilizadas principalmente no formato de relatórios, gráficos e planilhas, todos em PDF, o que limita a interatividade e o manuseio dessas informações pelo cidadão. Conforme o entrevistado B, "as planilhas são boas, mas muito grandes, muitos números". Quanto aos relatórios, o entrevistado A reconhece que os mesmos são arquivos pesados e muito grandes, o que exigiria da equipe pensar em documentos mais resumidos e informações mais simplificadas.

\section{c) O portal}

\section{Objetivo do portal}

Os entrevistados têm visões diferentes quanto aos objetivos do portal. Este seria um instrumento para: controle social; contraposição ao discurso governamental; prestação de serviço e avaliação da gestão governamental. No entanto, seja qual for o objetivo pensado para o portal, há um consenso, entre os entrevistados, de que este não foi atingido.

\section{Avaliação}

A avaliação interna do portal dar-se-á de forma assistemática, não planejada e sem periodicidade. O procedimento é essencialmente subjetivo, conforme fala a seguir:

\footnotetext{
Toda vez eu abro ele e olho - nossa! O que está faltando. Até por isso a gente faz consulta aos outros sites de outros estados para ver o que esses caras melhoraram que a gente poderia melhorar. (Entrevistado $\mathrm{E}$ )
}

O portal ainda não é objeto de avaliação da Gerência de Avaliação e Desempenho da Gestão Governamental, embora seja um produto da Superintendência de Controle Interno. A única avaliação pela qual o portal foi submetido foi a realizada pelo Índice de Transparência, em junho de 2010, a partir de três critérios: usabilidade, conteúdo, série histórica e frequência de atualização. Nessa avaliação, Goiás ficou na 12 a posição, como exposto anteriormente. 


\section{d) Participação do cidadão}

Os entrevistados argumentam que o público alvo do site é a sociedade, o povo, a população. Mas todos concordam que a participação do cidadão ainda é muito pequena. Isso, segundo eles, devido ao desconhecimento sobre o portal. Para os entrevistados, de um modo geral, o site precisa ser divulgado, pois os cidadãos não o conhecem. Conforme o entrevistado $O$, é necessário haver uma massificação na divulgação do site.

Eu entendo que o site, não só a forma, o site em si, mas todos os canais de divulgação que permitem o controle social eles são pouco divulgados pelos governos.

Essa falta de conhecimento e acesso ao site é generalizada. De acordo com os entrevistados, tanto do público interno (servidores públicos estaduais), quanto do público externo. Mas ninguém soube precisar a quantidade de pessoas que acessam o site, porque não há pesquisa e nem contagem de acesso, porém, os entrevistados afirmaram categoricamente que o acesso é muito pequeno.

$\mathrm{O}$ entrevistado $\mathrm{V}$ acredita que o portal ainda não tem colaborado para a participação do cidadão,

(...) porque ele nem sabe que existe. Essa é uma etapa agora para a gente desenvolver - seria com sensibilização, mostrar para o público que o portal existe e o seu objetivo.

De acordo com o entrevistado $B$, o cidadão comum usa bem mais o portal do que o servidor público estadual, devido a interesses específicos, principalmente as pessoas da universidade e da imprensa.

Além da falta de divulgação, os entrevistados disseram ter consciência de que uma pessoa com baixa escolaridade tem dificuldade de usar o sítio. Conforme os membros da equipe do portal, a acessibilidade é uma questão que está sempre em pauta. Mas ainda é um problema a ser resolvido, porque o cidadão, para acessar, conforme o entrevistado $O$, precisa ter domínio tecnológico. $O$ acesso baixo e o público restrito, conforme o entrevistado 0 , traduzem-se em um trabalho no site sem retorno da população.

No portal, a participação do cidadão resume-se ao "fale conosco", e-mail e telefone disponibilizados. Mas, de acordo com os entrevistados B, O e E, a participação é, em sua maioria, por e-mail. E, em grande parte, é de denúncia ou dúvidas que são, segundo eles, encaminhadas para os devidos setores o mais rápido possível. 


\section{Estrutura do portal}

Acessibilidade e navegabilidade ainda são obstáculos para a equipe do portal. E pontos de controvérsia. Para alguns, é necessário ainda tornar o portal mais "amigável para o usuário".

(...) a questão da acessibilidade é fundamental. Agora, nós somos conscientes das dificuldades. Uma pessoa analfabeta, ela não sabe entrar, mas a filha dele pode entrar e dizer - Oh, pai! Tá acontecendo isso - então a linguagem tem de ser bem fácil. (...) Então, como ele é feito em quadros e tal, só quem vai navegar é quem tem interesse. São pessoas que estão analisando, estudando, que usam aquilo como uma ferramenta. Mas não é para a sociedade usar. (Entrevistado B)

Já, para o entrevistado $E$, as informações estão bem dispostas no site e são fáceis de serem encontradas, apesar da pouca interatividade:

(...) você consegue, passando o olho na página inicial do site, ver as principais informações dele. Consegue identificar de forma mais simples e, com três clicks, você abre ela. Mas, falta interatividade.

Para acessar algumas informações no site é necessário digitar CPF, CNPJ. Sobre isso, o entrevistado B faz uma crítica:

Como é que eu vou saber seu CPF para saber se você recebeu diária. Eu tenho que botar um B e aparecer todas pessoas com B para eu tocar no [x] para eu saber para onde ele viajou, para onde ele pegou a diária.

Outra limitação apontada por um dos entrevistados foi a ausência de contagem de acesso. O levantamento do perfil do usuário do portal é também uma demanda dos entrevistados.

O site, segundo a equipe, é atualizado diariamente, no que diz respeito a notícias e despesas. Convênios, transferência para municípios, arrecadação do estado são disponibilizados mensalmente. Outras informações, como a lista de servidores, não têm periodicidade definida.

\section{e) Transparência}

A transparência, para os entrevistados, é muito mais do que a mera publicidade das contas públicas. De um modo geral, todos enfatizam a importância da "explicação da informação", das etapas do processo, como fica evidenciado na fala 
do entrevistado $\mathrm{E}$.

Transparência é uma evolução do princípio da publicidade. Temos que mostrar para a população não só as entradas e saídas dos processos da administração pública, Mas como eles são processados. Por que dizem que a administração pública é tão demorada? Peraí, tem mais coisas aí. Isso tem que ser mostrado. Então, eu acho que transparência é isso. Você deve dar a conhecer para toda a população todo o processo - entrada, processamento e saída deles.

Mas o entrevistado E enfatiza que o portal ainda não consegue representar essa concepção de transparência. $O$ entrevistado $B$ também defende essa concepção de que se deve explicar a motivação do gasto do dinheiro público. E faz uma crítica:

Agora o governo não quer dar publicidade, por isso que é elitizada a questão da transparência. Só quem olha são as pessoas ligadas ao meio. $\mathrm{O}$ entrevistado $\mathrm{B}$ ressalta ainda que a transparência está muito ligada à moralidade, que, consequentemente, traz eficiência gerencial. E, segundo ele, a eficiência gerencial traz maior retorno para a sociedade de uma forma geral. Porque, com a moralidade, as crianças podem ter uma boa merenda (...) e o instrumental da transparência traz isso.

O discurso do entrevistado $O$ vai também nesta direção da transparência enquanto uma questão moral e de dever público. Para o entrevistado A, qualquer sistema tem a transparência, só que ela não é satisfatória ao ponto de a pessoa se sentir motivada a utilizá-lo. Conforme ele, é necessário facilitar isso, envolver o cidadão, porque ele não está sensibilizado e consciente dessa questão.

\section{Conclusões}

O regime democrático possibilitou à população a participação política e o controle social das ações governamentais, ofereceu subsídios legais para essa participação, mas ainda não consegue suprir o gap entre direitos constituídos e direitos exercidos. Um exemplo dessa situação é a falta de conhecimento e/ou pequeno acesso da população aos portais transparência no país. O direito de conhecer as contas públicas foi adquirido. Os problemas são falta de divulgação desse instrumento de controle social, dificuldade de acesso e de compreensão, pois as informações não estão na linguagem do cidadão comum. 
O Portal Transparência Goiás ilustra essa situação. Estabelecido e mantido sob um aparato legal, não consegue ser um instrumento de conhecimento e participação da sociedade nas ações governamentais, através do exercício do controle social. Abaixo são observados alguns dos obstáculos para essa prática da cidadania, que concluem a pesquisa.

1. O Portal Transparência Goiás não tem divulgação. Não há campanhas publicitárias na TV, rádio, jornal. Em mais de $50 \%$ dos portais mantidos pelo governo do Estado, não há link de acesso direto ao Portal Transparência Goiás, como exigido em lei;

2. A equipe é insuficiente e pouco qualificada para exercer a função;

3. O acesso da equipe às informações nos órgãos e unidades do governo do Estado de Goiás é difícil. O acesso à informação é demorado e sem garantias. Há hierarquia na busca das informações; resistência no fornecimento das informações; desinteresse em colaborar com o portal quando as informações não são as exigidas pela lei; a interação entre os demais órgãos e unidades e a equipe do portal é muito pequena e não há programas de sensibilização junto ao servidor público para conhecer e colaborar com o portal;

4. O portal tem uma linguagem técnica que dificulta o acesso;

5. Apresenta informações pouco explicativas e, para acessar alguns dados, exige identificação;

6. Não há avaliação interna do portal;

7. O portal não é um foco de interesse do governo;

8. O portal não está cumprido seus objetivos, descritos no decreto que o regula e divulgado no sítio.

Os itens listados acima revelam que: a) a divulgação dos dados e informações relativos à execução orçamentária e financeira dos órgãos e entidades da administração pública estadual direta e indireta, não é totalmente feita em conformidade com a legislação; b) não há incentivo à participação do cidadão nos processos de planejamento, acompanhamento e avaliação das ações da gestão pública, contribuindo pela efetividade do controle social.

Essas constatações chamam a atenção para o fato de que a transparência ainda tem sido tratada como uma questão menor pela gestão pública, mesmo que tenha havido êxitos no processo. O descaso dos administradores públicos com o acesso do cidadão à informação é um exemplo de que há um longo caminho para ser percorrido até a accountability. 
Abstract: This article presents the findings of a study that examined the how the state government of Goiás has acted in order to make public management more transparent and responsive. The object of the study is the Portal Transparência Goiás as well as the channels that feed its information. The results shows that transparency is still treated as a minor issue for the government, although there have been some achievements. Keywords: State, Accountability, Transparency, Public Management, Information.

\section{Referências}

AKUTSU, Luiz \& PINHO, José Antonio G. de. "Sociedade da informação, accountability e democracia delegativa: investigação em portais de governo no Brasil". Revista de Administração Pública, v. 36, n. 5, set./out. 2002. p. 180-193.

BRESSER-PEREIRA, Luis Carlos. "As formas de responsabilização na gestão pública”. In: BRESSER PEREIRA, Luiz Carlos \& GRAU, Nuria Cunill (Coord.). Responsabilização na administração pública. São Paulo: Clad/Fundap, 2006

"A reforma gerencial de 1995". In: Belmiro, V. Jobim Castor; L.C Bresser Pereira e outros (Org.). Burocracia e reforma do Estado. Cadernos Adenauer, n. 3. São Paulo: Fundação Konrad Adenauer, 2001.

CALPING EDUCATION FUND. Report California Budget Transparency 2.0, 2009. Disponível em: <http://www.calpirg.org/reports/caf/california-budget-transparency-20>. Acesso em 23 de novembro de 2012.

CAMPOS, Anna Maria. "Accountability: quando poderemos traduzi-la para o português?" Revista de administração pública, Rio de Janeiro, v. 24, n. 2: 30-50, Fev./Abr. 1990. p. 30-50.

CLAD. La responsabilización em la nueva gestión pública latino-americana. Buenos Aires: Eudeba, 2000.

CULAU, A \& FORTIS, M. "Transparência e Controle Social na Administração Pública Brasileira: avaliação das principais inovações introduzidas pela Lei de Responsabilidade Fiscal". XI Congresso Internacional del CLAD, Ciudad da Guatemala, 2006.

CUNHA, Maria Alexandra V. C. "Meios eletrônicos e transparência: a interação do vereador brasileiro com o cidadão e o poder executivo". Paper apresentado no X Congresso Internacional del CLAD. 18-21 de outubro, Santiago, 2005.

DAHL, Robert. Polyarchy: participation and opposition. New Harven: Yale University Press, 1971. 
HOROCHOVSKI, Rodrigo Rossi. "Accountability e seus mecanismos: um balanço teórico". Em: 60 Encontro da ABCP. Unicamp, Campinas, 2008.

MIGUEL, Luiz Felipe. "Impasse da accountability: dilemas e alternativas da representação política". Revista de Sociologia e Política. Curitiba, 25, p. 25-38, 2005.

MOTA, Ana Carolina Yoshida Irano de. Accountability no Brasil: os cidadãos e seus meios institucionais de controle dos representantes. Tese de doutoramento. São Paulo: USP, 2006.

OECD Best Practices for Budget Transparency, Organization for Economic Cooperation and Development, maio de 2001. Disponível em <http://www.oecd. org/gov/budgetingandpublicexpenditures/1905258.pdf>. Acessso em 15 de agosto de 2012.

O'DONNELL, Guillermo. "Accountability Horizontal e novas poliarquias". Lua Nova, São Paulo n. 44, 1998. p. 27-54

PERUZZOTTI, Enrique \& SMULOVITZ, Catalina. Societal accountability. "The other side of control". In: Peruzzoti, E \& SMULOVITZ, C (Org.) Enforcing the rule of law: the politics of societal accountability in Latin America. Pittsburgh: University of Pittsburgh Press, 2000.

PINHO, José Antonio Gomes. "Investigando portais de governo eletrônico de estados no Brasil: muita tecnologia, pouca democracia". Revista de Administração Pública 42(3) Rio de Janeiro, 471-93, maio/junho, 2008. p. 471-493.

PUTNAM, Robert. Comunidade e Democracia: a experiência da Itália moderna. Rio de Janeiro: Fundação Getúlio Vargas, 2000.

RODRIGUES, Isabela França \& BRASIL, Flávia de Paula Duque. “Contribuições e Potenciais da Governança Eletrônica para a Democracia: Transparência, Controle Público e Participação Cidadã - uma análise dos sítios das secretarias de Estado de Minas Gerais". Paper apresentado no III Congresso Consad de Gestão Pública. 15-17 de março, Brasília, 2010.

SANTANA, Jorge José B. et al. "Transparência fiscal eletrônica: uma análise dos níveis de transparência apresentados nos sites dos poderes e órgãos dos Estados e do Distrito Federal do Brasil". Revista de Educação e Pesquisa em Contabilidade. v. 3 p.62-84, 2009.

VISHWANATH, Tara \& KAUFMANN, Daniel. Towards Transparency in Finance and Governance, 1999. Disponível em <http://papers.ssrn.com/sol3/papers. cfm?abstract_id=258978> Acesso em 14 de novembro de 2012. 